\title{
A Review of Some Significant Research Trends in Yarn Texturising
}

\author{
Gokarneshan N*, K Velumani, Aishwarya Sree and Sethupathy \\ Department of Textile Technology, India \\ *Corresponding author: Gokarneshan N, Department of Textile Technology, Tamil Nadu, India
}

Submission: 畊 February 27, 2018; Published: 眥 March 08, 2018

\begin{abstract}
The article reviews some significant research trends in yarn texturising. Investigations have been carried out on the effect of yarn feed and process parameters used in the production of air-jet textured yarn on compression and recovery behavior of air-jet textured yarn fabric. Fabric low load compression-recovery behavior has been analyzed by defining compression parameter, recovery parameter and resiliency. The crimp features of false twist textured yarns have been determined by a new method by applying computer vision and image processing method. It enables to obtain accurate test results in a speedier manner compared with other existing methods. The properties of air jet textured yarn has been predicted by artificial neural network model and the performance of the model has been is compared with response surface model based on multiple non-linear regression analysis. Studies have been carried out on the influence of process parameters on properties of polyester/viscose blended air jet textured yarns.
\end{abstract}

Keywords: Air jet textured yarns; Compression properties; Algorithms; Image tracking; ANN; Regression model; Blended yarn; Physical bulk

\section{Introduction}

Texturing is the method by which compact structure of continuous filament yarn is modified to impart texture to filament bundle, which will provide bulk like spun yarn for better comfort characteristics to the fabrics made from them. In air-jet texturing, filament yarn with certain overfeed is fed in cold supersonic airstream to produce entangled filament bulked yarn of low extension ability. It is known that air-jet textured yarn has certainly good resemblance of spun yarn due to unique structure. The lowload compression behavior of woven fabrics is very significant in term of handle and comfort. Compressibility is one of the important properties of the fabric which affects the softness and fullness of the fabric. Fabric compression is strongly correlated to its geometry, and the structural properties of yarn and fibre, from which it is constructed. It is also useful for fabric handling during garment manufacturing. In addition, it is found that the analysis of the pressure thickness relationship may shed light on the structure of the fabrics. The analysis of compression behavior of textile ensemble was first studied, and developed the compression meter and defined the association between the thickness of fabric and the compression force [1]. Later a model has been introduced based on the analysis of compression behavior of woolen fabric [2]. This model was considerably extended by many researchers to elaborate the compression properties of nonwoven, woven and knitted fabrics [3-5].

During 1950, a new branch was created in the textile industry as texturizing of continuous filament yarn [6]. Texturizing meant to create a permanent deformation of the filament yarns, which creates different properties. In general texturizing is done by one of these three methods, viz. mechanical, thermal-mechanical and chemical-mechanical. Texturizing by the false twist method is the most important and practical method to produce these yarns. Various factors affect the shape and crimp properties of textured yarn. Important factors are filaments chemical structure, yarn count, number of filaments, shape of surface area and factors related to system such as yarn motion systems, yarn time passes in each step, type of heater and its length and temperature. The computer vision in research and quality control procedures is applicable. A system has been introduced that allows further investigation of the samples tested at high speed and accuracy without any contact with the samples [7]. This system was able to detecttangle and sensitive to the diameter changes.

Air-jet texturing is one of the several processes used to convert synthetic filament yarns to textured yarns and is the most versatile of all known texturing methods. The air-jet texturing process is widely known for its ability to produce continuous filament yarns with spun yarn like appearance. The process converts flat filament yarns into bulky spun like yarns. It involves overfeeding of multifilament supply yarns from a creel into an air-jet via an optional yarn wetting device. Action of the compressed turbulent cold air stream causes overfed individual filaments to form loops and entangle with each other. 
Influence of Air Jet Texturing Factors on Compression Properties of Woven Fabrics

The compression properties of nonwoven geo textile has been studied by evaluating two parameters $\alpha$ and $\beta$ to represent the compression and recovery curves respectively by an empirical model [8]. The compression curve has been analyzed by dividing it in five zones and defined the regression constant for each [9]. Fabric geometrical parameter has been used as an input to an artificial neural network model to predict fabric compression properties of different cotton woven fabrics and compared the modeled results with corresponding Kawabata data [10]. Studies have been done on the effect of feed yarn fineness and process parameter of core and effect of air-jet textured yarn on fabric compression properties $[11,12]$.

Efforts have been taken at explaining the pressure-thickness relationship of woven air-jet textured yarn fabrics in low-load regions by suitable mathematical coefficients using empirical modeling. The individual effect of feed yarn parameters like linear density per filament and process parameters like overfeed, air pressure and texturing speed on the air-jet textured yarn fabric compression-recovery behavior has been studied. The contribution of each yarn feed and process parameters on the measured fabric properties is also evaluated in term of potential contribution and normalized regression coefficient.

Based on the results of multiple regression model and contribution analysis of the different air-jet texturing variables on textured yarn fabric properties, the following conclusions can be drawn. Overfeed percentage is an important factor in determining the air-jet textured fabric compression properties [13]. A steep increase is visible in all textured yarn properties with the increase in overfeed percentage. The second most influential variable among the four variables studied is linear density per filament. Linear density per filament of parent yarn affects the fabric resiliency, thickness, compression parameter and recovery parameter significantly. Although air pressure affects fabric properties the least among variables studied but it has significant contribution to all fabric properties.

\section{Image Processing for Assessment of False Twist Textured Yarns}

A group of researchers used methods such as the measurement of yarn package density, thickness of the fabric production and the amount of water carried by the texture yarn in order to evaluate buckling and stitch density. The main purpose of texturizing the air jet is to produce bulky yarns. Bulk and density of loops is important factors for the quality control of texture yarns [14]. In recent years, many research projects have been carried out to present new methods for determination of crimp, especially crimp concentration in texture yarns. With the advent of modern computers and new programming tools, the use of computer vision for quality control and test products is increasing [15]. The structure of false twisted yarn is similar to the fractal shape. Therefore, some researchers evaluate the crimp of textured yarn based on their work on the use of fractal geometry. In this study, a new method to quantify the crimp amount of single filaments has been developed. Also the effect of the filaments in the false twist texture yarn in this new method is studied.

This study is a novel approach using computer vision to determine the percentage of crimp concentration in false twist textured yarn so that the test results with accuracy are achieved more quickly than other existing methods. Also, the study of placing the filaments in the false twist texture yarn is considered as the aim of this research [16]. Experiments performed on images on false twist textured yarn include determination of orientation index and mean angle filament alignment index. In the mean angle of orientation, with a correlation coefficient of more than $95 \%$, the yarn is found to have a linear relationship with the amount of crimp concentration. The effect of production variables (twisting, temperature and speed of texturizing) on the arrangement of the filaments in the false twist texture yarn in this new method is also studied.

\section{It is observed that}

(i) Increasing texturizing twist causes a decrease in orientation along the yarn axis,

(ii) Increasing heater temperature results in deviation of filaments from the yarn axis

(iii) Increment of texturizing speed has high orientation as a result.

Prediction in real life textile applications is becoming essential and common. Prediction of the expected behavior/performance of a process or product, before it is made, is required to minimize or reduce the set-up cost and set-up time. Alternatively, there could be situations where a decision is required to be taken on the past data for which a normal human brain has limitations of drawing out interferences. Ability to predict properties of yarns accurately has become a challenge due to the highly non-linear interactive behavior of fibres and yarns, especially under dynamics conditions [17].

\section{Prediction of Air Jet Textured Yarn Properties by Comparing ANN and Regression Models}

Artificial neural network (ANN) has been found useful for many predictions related problem in textiles. Applications of ANN model cover a broader area in textiles such as prediction of characteristics of textile; identification, classification and analysis of defects; process optimization; marketing and planning [18].

A number of researchers have reported the application of ANN for prediction of yarn characteristics from fibre properties [19-21]. To simulate the effect of process variables on product characteristics, ANN is being used by some of research workers [2224]. Among the various techniques viable for texturing of filament yarn; air-jet texturing is most versatile method. It is an unique and purely a mechanical method in which filament yarns with certain amount of overfeed are fed in cold supersonic air stream 
to produce entangled filaments bulked yarn of low extensibility. Being a purely mechanical process, it can be used for producing both thermoplastic and non-thermoplastic filament yarns [25-29]. Also, only a few research papers are available on the use of ANN for predicting air-jet textured yarn properties [30].

An attempt has been made to study the suitability of modeling techniques for predicting the air-jet textured yarn properties, viz physical bulk, instability and loss in tenacity. Based on the experimental results, air-textured yarn properties are predicted by ANN and regression models within the range of input data set. The results obtained by prediction of two models are compared with experimental values.

The artificial neural network is found capable of predicting the properties of air-textured yarn with lower level of error. The neural network is more effective in predicting the yarn instability than that of regression model. There is good agreement between the values of neural network test data set and validation data set for textured yarn properties. Mean error per cent of prediction of neural network shows better results for test data set and validation data set, in case of instability and loss in tenacity values, while it is comparable to the of regression model for physical bulk values.

\section{Optimization in Air Jet Texturing of Polyester/Viscose Blended Yarns}

Air-jet texturing is a mechanical method and, therefore, thermoplastic and non-thermoplastic filament yarns can be used for air-jet texturing. Air-jet texturing thus provides excellent potential for combining two or more multifilament yarns into a more or less intimately blended and coherent structure. In the present study, an attempt has been made to predict the optimum process parameters on the basis of yarn physical bulk, instability and tenacity for producing good quality polyester/viscose blended air-jet textured yarns [31].

Increasing texturing speed reduces the yarn physical bulk and increases the instability and tenacity. With the increase in air pressure or overfeed, physical bulk and instability increase and tenacity reduces. It has been reported that the optimum air-jet texturing process parameters to be used to produce $\mathrm{P} / \mathrm{V}$ blended air-jet textured yarns with 3:2:1 weightage to low instability, high physical bulk and high tenacity of the yarns. It is also observed that lower texturing speed is necessary for producing good quality airjet textured yarn for any blend.

Generally, the prediction of optimum process conditions to achieve low instability values in the air-jet textured yarns does not seem to be very effective. For $50 / 50 \mathrm{P} / \mathrm{V}$ and $67 / 33 \mathrm{P} / \mathrm{V}$ blends the predicted values of instability under optimum process conditions are found to be higher than they actually observed values, whereas the predicted values of physical bulk are lower than they actually obtained values under the same processing conditions. This means that these two blends behave better than expected during the airjet texturing process. The predicted values and the actual values of the physical bulk and tenacity of the yarns produced at optimum processing conditions are found to be closely correlated. It is also found that $100 \%$ viscose and $100 \%$ polyester yarns require high overfeed to generate high bulk and low instability in the textured yarn.

\section{Conclusion}

The individual effect of feed yarn properties and air-jet process variables in the production of air-jet textured yarn has been studied in term of potential contribution and normalized regression coefficient on fabric low load compression behavior. Fabric low load compression-recovery behavior has been analyzed by defining compression parameter, recovery parameter and resiliency. Analysis shows that most dominating factor to explain the air-jet textured yarn fabric low-load compression properties is overfeed percentage, while linear density per filament is most dominating factor affecting fabric resiliency. Computer vision and image processing technique have been used to determine the crimp features of false twist textured yarn. It enables to achieve faster test results in comparison with existing methods. The mean angle of filament orientation in false twist textured yarns with different texturizing variables (heater temperature, texturizing speed and twist) is determined. Similarly, the direct tracking algorithms to achieve a good correlation with crimp contraction are also used. The results show that by this new method a correlation coefficient of more than $95 \%$ is achieved between mean orientation angle and crimp contraction. In the prediction of air jet textured yarn properties ANN model has been used and compared with response surface model based on multiple non-linear regression analysis. The input variables considered are linear density per filament, overfeed, air-pressure and texturing-speed, since these influence the yarn properties considerably. Artificial neural network is able to forecast the air-jet textured yarn properties based on selected input parameters with a lower level of errors than the regression models. The validation data set, which is used to validate both the model, shows lower level of mean error per cent in case of ANN than in case of regression model. The process parameters in the case of air texturing of polyester/viscose blended yarns have been optimized. There is reduction in yarn physical bulk, accompanied by increase in yarn instability and tenacity. With increasing air pressure or overfeed, the physical bulk and instability increase, whereas tenacity reduces. Regression equations for the prediction of airjet textured yarns properties have also been derived. On the basis of the regression equations the optimum process parameters for producing good quality air-jet textured yarns have been obtained, considering that the yarns with lowest instability, and high bulk and tenacity are desirable. Yarn instability is accorded the highest weightage while bulk is given intermediate and tenacity the lowest weightage in order to find out the combination of parameters that will produce yarns of low instability, high bulk and high tenacity values.

\section{References}

1. Schiefer HF (1933) The Compressometer: An instrument for evaluating the thickness, compressibility and compressional resilience of textiles and similar materials. Text Res J 3(10): 505-513. 
2. Van Wyk CM (1946) 20-Note on the compressibility of wool. J Text Inst 37(12): T285-T292.

3. De Jong S, Snaith JW, Michie NA (1986) A mechanical model for the lateral compression of woven fabrics. Text Res J 56(12): 759-767.

4. Hu J, Newton A (1997) Low-load lateral-compression behaviour of woven fabrics. J Text Inst 88(3): 242-254.

5. Taylor PM, Pollet DM (2002) Static low-load lateral compression of fabrics. Text Res J 72(11): 983-990.

6. Hearl J, Hollick L (2001) Yarn Texturing Technology, ( $1^{\text {st }}$ edn), The Textile Institute, Woodhead Publishing Ltd, Elsevier, UK.

7. Millman MP, Ascar M, Jackson (2001) Computer vision for textured yarn interlace (nip) measurements at high speeds. M R Mechatronics 11(8): 1025-1038.

8. Kothari VK, Das A (1993) Compressional behaviour of nonwoven geotextiles. Geotext Geomembrn 11(3): 235-253.

9. Matasudaira M, Qin H (1995) Features and mechanical parameters of a fabric's compressional property. J Text Inst 86(3): 476-486.

10. Gurumurthy BR (2007) Prediction of fabric compressive properties using artificial neural networks. Autex Res J 7(1): 176

11. Rengasamy RS, Das BR, Patil YB (2009) Ordering manager. Open Text J 252, pp. 1-69.

12. Hearle JWS (2008) Physical properties of textile fibers. (4 ${ }^{\text {th }}$ edn), Woodhead Publishing, Cambridge, UK.

13. Baldua RK, Rengasamy RS, Kothari VK (2016) Effect of linear density of feed yarn filaments and air-jet texturing process variables on compressional properties of woven fabrics. Indian journal of fibre and textile research 41(1): 47-54.

14. Yousefzadeh M, Amani-Tehran M, Latifi M, Mojtahedi MR (2005) Determination of crimp indexes of false twist and knit de knit textured yarns using computer vision. Amirkabir J 16: 53-58.

15. Shitong W, Fu-lai C, Fusong X (2008) A novel image thresholding method based on Parzen window estimate. Pattern Recognition 41(1): 117-129.

16. Maleki M, Latifi, Amani M (2009) A novel image thresholding method based on Parzen window estimate. Int J Nanotechnol 6(12): 1131-1154.

17. Ghaderpanah P, Mokhtari F, Latifi M (2015) Evaluation of false-twist textured yarns by image processing. Indian journal of fibres and textile research 40(4): 399-404.
18. Mukhopadhyay A (2002) Text Asia 4: 35.

19. Demiryürek O, Koc E (2009) Predicting the unevenness of polyester/ viscose blended open-end rotor spun yarns using artificial neural network and statistical models. Fiber Polym 10(2): 237-245.

20. Ureyen ME, Gurkan P (2008) Comparison of artificial neural network and linear regression models for prediction of ring spun yarn properties. I. Prediction of yarn tensile properties. Fiber Polym 9(1): 87-91.

21. Ureyen ME, Gurkan P (2008) Comparison of artificial neural network and linear regression models for prediction of ring spun yarn properties. II. Prediction of yarn hairiness and unevenness. Fiber Polym 9(1): 92-96.

22. Midha VK (2011) J Text Inst 102(8): 668.

23. Rabbi A, Nasouri K, Barharambeygi H, Shoushtari AM, Babaei MR (2012) RSM and ANN approaches for modeling and optimizing of electrospun polyurethane nanofibers morphology. Fiber Polym 13(8): 1007-1014.

24. Rajamanickam R, Hansan SM, Jayaramen S (1997) Analysis of the modeling methodologies for predicting the strength of air-jet spun yarns. Text Res J 67(1): 39-44.

25. Mahish SS, Punj SK (2010) Optimization of process parameters in air-jet texturing of polyester/viscose blended yarns. Indian journal of fibre and textile research 35(3): 213-221.

26. Yadav VK, Kothari VK (2004) Optimization of process parameters in air-jet texturing of Prediction of air-jet textured yarn properties using statistical method and neural work polyester/viscose blended yarns. Indian J Fibre Text Res 29(2): 149-156.

27. Sengupta AK, Kothari VK, Rengasamy RS (1990) Chem Text-Ind, 40/92 998: E113.

28. (1991) Technical Information. Taslan Bulletin, TS-4.

29. Fausett L (1994) Fundamentals of neural networks. Prentice Hall, New Jersey, USA, p. 289.

30. Demir A, Acar M, Wray GR (1988) Air-jet textured yarns: the effects of process and supply yarn parameters on the properties of textured yarns. Text Res J 58: 318-328.

31. Acar M, Turton RK, Wray GR (1986) An analysis of the air-jet yarntexturing process part VI: the mechanism of loop formation. J Text Inst 77: 247 .
Creative Commons Attribution 4.0

International License

For possible submissions Click Here

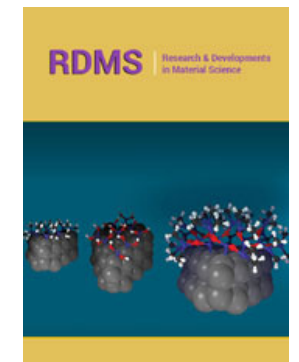

Research \& Development in Material Science

\section{Benefits of Publishing with us}

- High-level peer review and editorial services

- Freely accessible online immediately upon publication

- Authors retain the copyright to their work

- Licensing it under a Creative Commons license

- Visibility through different online platforms 